\title{
Mineral resources in the age of climate adaptation and resilience
}

Invited contribution to the JIE Forum related to a special issue on adaptation and resilience, $3^{\text {rd }}$ revision following reviewers' comments and chief editor and handling editor comments, dated 29 July 2019.

Manuscript ID is 18-JIE-6033.R2

\section{Raimund Bleischwitz}

University College London, London, United Kingdom of Great Britain and Northern Ireland.

Email: r.bleischwitz@ucl.ac.uk

\section{Abstract}

This article discusses issues on resources availability to achieve climate adaptation and resilience for cities and infrastructures. In the age of climate change, there could be cascading failures through a range of infrastructure breakdowns. Direct and indirect damage costs could exceed what had been estimated in traditional risk assessments. This could be exacerbated through abrupt price peaks in international supply chains of minerals, and through events happening in remote parts of the world that affect extraction and vulnerable industries. The core argument made here is one of feedbacks: climate adaptation has significant resource implications, and how resources are being used will have implications on climate strategies. Industrial Ecology has a role to play assessing those interactions and providing a better grasp of the spatial dimension of material flows, partly to track those flows and align them to specific actors, and partly to address interlinkages across different flows and their stocks ('the resource nexus'). Methodological novelties are needed to better understand the resource base and the socio-economic dimension, especially on innovations and transitions that can help to cope with the challenges ahead. Altogether this would enable research to establish an evidence base on sustainable materials to deliver parts of the UN Sustainable Development Goals (SDGs) and to re-assess infrastructure assets and the mineral resources in the age of climate adaptation and resilience.

Keywords: resource management, circular economy, climate change, materials efficiency, methods, economic analysis

Conflict of interest statement: The authors have no conflict to declare.

\section{Address Correspondence to:}

Raimund Bleischwitz

University College London (UCL ISR / BSEER), UCL Institute for Sustainable Resources, Central House 14 Upper Woburn Place London WC1H ONNLondon, United Kingdom of Great Britain and Northern Ireland. 


\section{Introduction}

Despite the ambitious long-term goal of the Paris Agreement to keep a global temperature rise this century well below 2 degrees Celsius above pre-industrial levels, climate change is ongoing. With the current $\mathrm{CO}_{2}$ concentrations reaching the highest levels in the past 800,000 years, average global temperatures are increasing, intensifying societal challenges of coping with: rising sea levels; shifting vegetation zones; and more frequent and intense natural hazards. The media discusses weather extremes such 'hothouse' of warm temperatures and the degree to which this might or might not be related to climate change. Academia explores risks of self-reinforcing feedbacks that could put the Earth system towards a planetary threshold and would likely cause serious disruptions to ecosystems, society, and economies (Steffen et al. 2018). Both angles - media and science - are difficult to test against evidence. What is evident, however, is the urgent need to incorporate adaptation and resilience within planning, especially for the built environment. Planners, investors, policy makers and other relevant stakeholders have no other choice but to face risks and get prepared for disruptions and shocks related to climate change. 'Expect the unexpected', originally coined by Oscar Wilde more than hundred years ago, is becoming a buzzword of modern management language.

This article seeks to develop a perspective for mineral resources towards climate adaptation and resilience. It attempts to offer a holistic view on: climate adaptation; minerals; the construction industry; and the built environment. Can industry deliver a supply of minerals in the quantities and qualities needed to cope with future demand? What type of systems thinking and strategies are required to deal with risks and uncertainties and maintain value creation for future generations? It is argued here that climate adaptation has significant resource implications, and how resources are being used has implications for climate strategies. This is more than just a technical or an engineering perspective; it aligns with the UN Sustainable Development Goals (SDGs). Such view on industrial systems, value chains and urban infrastructures is not only enshrined in SDG9 on industrialization, SDG11 on cities, and SDG13 on climate change, but can also be seen as essential for provisioning basic services to the people and for creating public values. This argument therefore adds a socio-economic perspective - in particular a concern for the poor and marginalized people and neighborhoods often lacking access to basic services such as affordable housing and energy (SDG7) and clean water (SDG6), and whose livelihoods are most vulnerable to impacts of climate change (Adger et al. 2014, Biggs et al. 2015).

\section{Challenging demand trends for minerals: New scarcities and the nexus}

Broader risks of resource availabilities and vulnerable infrastructures in the built environment have been overlooked in many climate debates. Both, however, matter not only for low carbon pathways but also their demand for copper, steel and a number of specialty metals such as lithium (Tokimatsu, K. et al. 2017). Urban systems and infrastructures are crucially dependent on a reliable supply of minerals and materials for a range of possible pathways. Are those resources available in the future, and can industry be expected to deliver?

More minerals are needed in the near future. In a recent report based on macro-economic modelling, the OECD (2018) expects global materials use to more than double from 79 Gt in 2011 to $167 \mathrm{Gt}$ in 2060. Non-metallic minerals, such as sand, gravel and limestone, represent more than half of total materials use, and are projected to increase from $37 \mathrm{Gt}$ in 2011 
to $86 \mathrm{Gt}$ in 2060 . These projections are broadly in line with others, such as Hatfield-Dodds et al. (2017) and UNEP's International Resource Panel (UNEP 2017). Assessing requirements for infrastructures and key goods and taking into account trends observed since 1950, Christman (2018) foresees that aluminum demand could even be eight times the current production levels by 2050 and the production of cement would need to grow by a factor of 7 to meet the 2050 level of demand.

All such projections underline the relevance of minerals for development. Foresight indeed requires careful analysis of demand drivers and possible innovations. The urbanization and infrastructure development in China triggered an unprecedented demand for cement over the last twenty years. The OECD estimates a stabilization in the future demand for construction minerals in China around the year 2025, in line with our observations on a saturation effect (Bleischwitz et al. 2018a). However such trends will unfold and a decoupling of GDP from the inputs of mineral resources occur in China and across the globe, it is clear that demand trends for mineral resources are upwards. Will the industry be able to deliver?

Geological scarcity may not appear to be an issue to meet expected demands for mineral resources (Meinert, Robinson, Nasser 2016; Christman 2018), as regional scarcities could be overcome by international trade. Research and complexity analysis however needs to address the dynamic nature of relationships between reserves, resources, cut-off grades and ore grades; the ability to account for local economic, social and environmental factors when performing global assessments; and the role that technology improvements play in increasing the availability of economically extractable mineral resources (Northey, Mudd and Werner 2018). As a result, the scale of investments required to produce high-volume and high-quality materials can be expected to increase, aggravated by the challenges described below (Fig 1). More than ever, the industry will be challenged to innovate and to attract investments risks and uncertainties. 


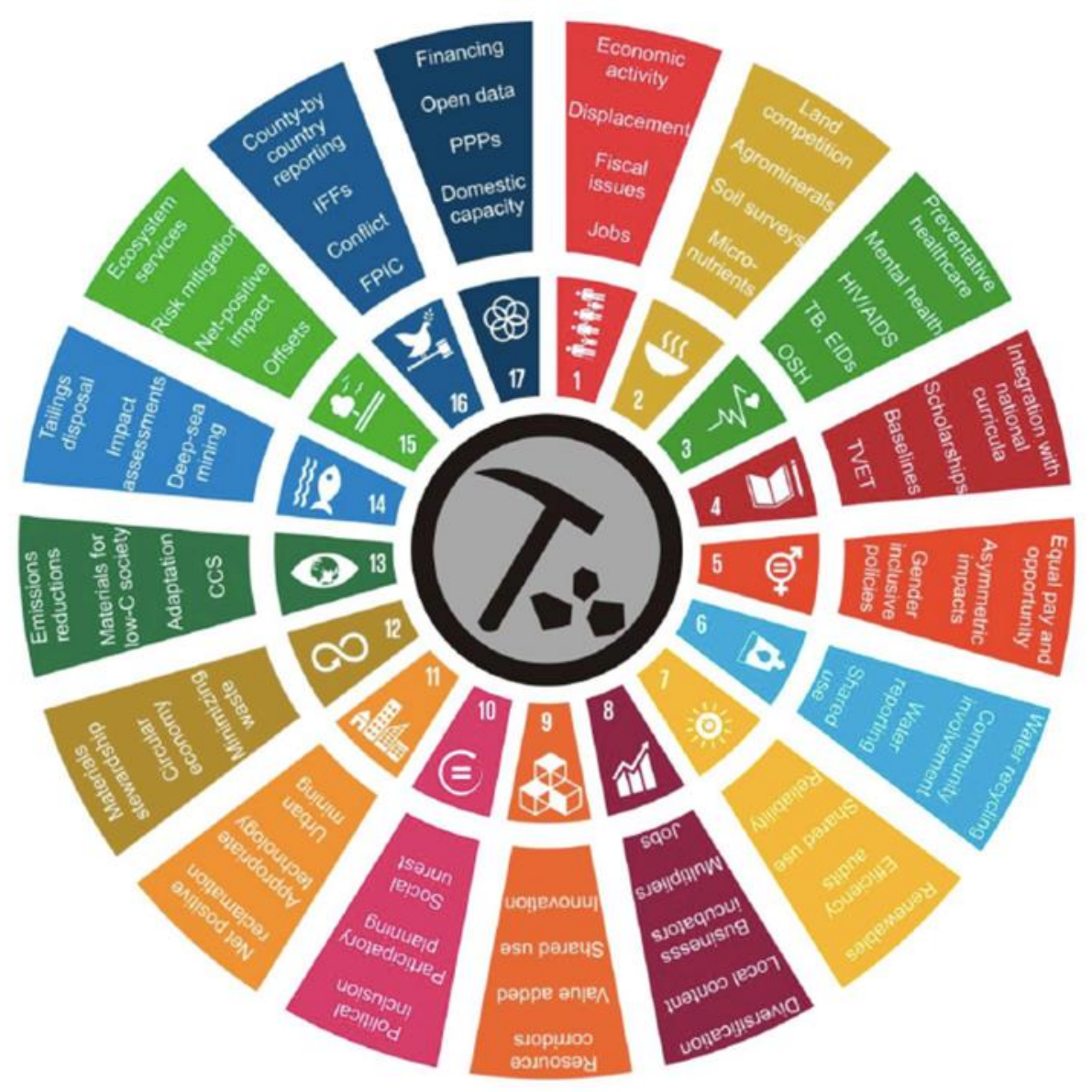

Figure 1: Issue areas concerning mining, minerals and sustainable development

Abbreviations: EIDs= emerging infectious diseases; $\mathrm{OSH}=$ occupational safety and health; TVET = technical, vocational, and education training; CCS = carbon capture and storage; IFFs = illicit financial flows; FPIC = free, prior and informed consent; PPPs = public and private partnerships.

Source: Columbia Center on Sustainable Investment, UNDP, UN Sustainable Development Solutions Network, World Economic Forum. 2016. Mapping Mining to the Sustainable Development Goals: An Atlas. unsdsn.org.

In order to match supply and demand, Industrial Ecology methods of material flow analysis (MFA) and indicators such as the 'material footprint' (Wiedmann et al 2013) help tracking the use of materials from mining to end-users at an international scale. Those methods have proven useful for contemporary debates on interdependencies and resource governance (Ali et al. 2017) and can be disseminated e.g. through UNEP's International Resource Panel (UNEP 2010, 2017). At more disaggregated levels, MFA models on key materials are needed such as the one established on aluminum, as are ways to integrate such data in macro-economic models (see Winning et al. 2018 on steel) as well as in corporate reporting. 
Energy and water are likely to be limiting factors for mining and along supply chains, as well as the sustainable management of the enormous amount of mining waste that would be generated (Christman 2018) and related interventions in biosphere integrity (Murgia, Bringezu and Schaldach 2016). Limits to growth - a well-known report to the Club of Rome in the early 70s of last century focusing on resource availabilities and new scarcities may emerge (Bleischwitz and Rentschler 2018: 283) at the intersection of climate impacts and related environmental pressures, resource governance and resilience. Managing extraction with a social license to operate under conditions of water stress and requirements for reliable energy in mining and during next stages of the supply chain is a real challenge.

The resource nexus is a powerful concept addressing resource interlinkages and new scarcities. It can be defined as a set of context-specific critical interlinkages between two or more natural resources used in delivery chains towards systems of provision for water, energy, food, land, and materials (Bleischwitz et al. 2018b, Fig 2).

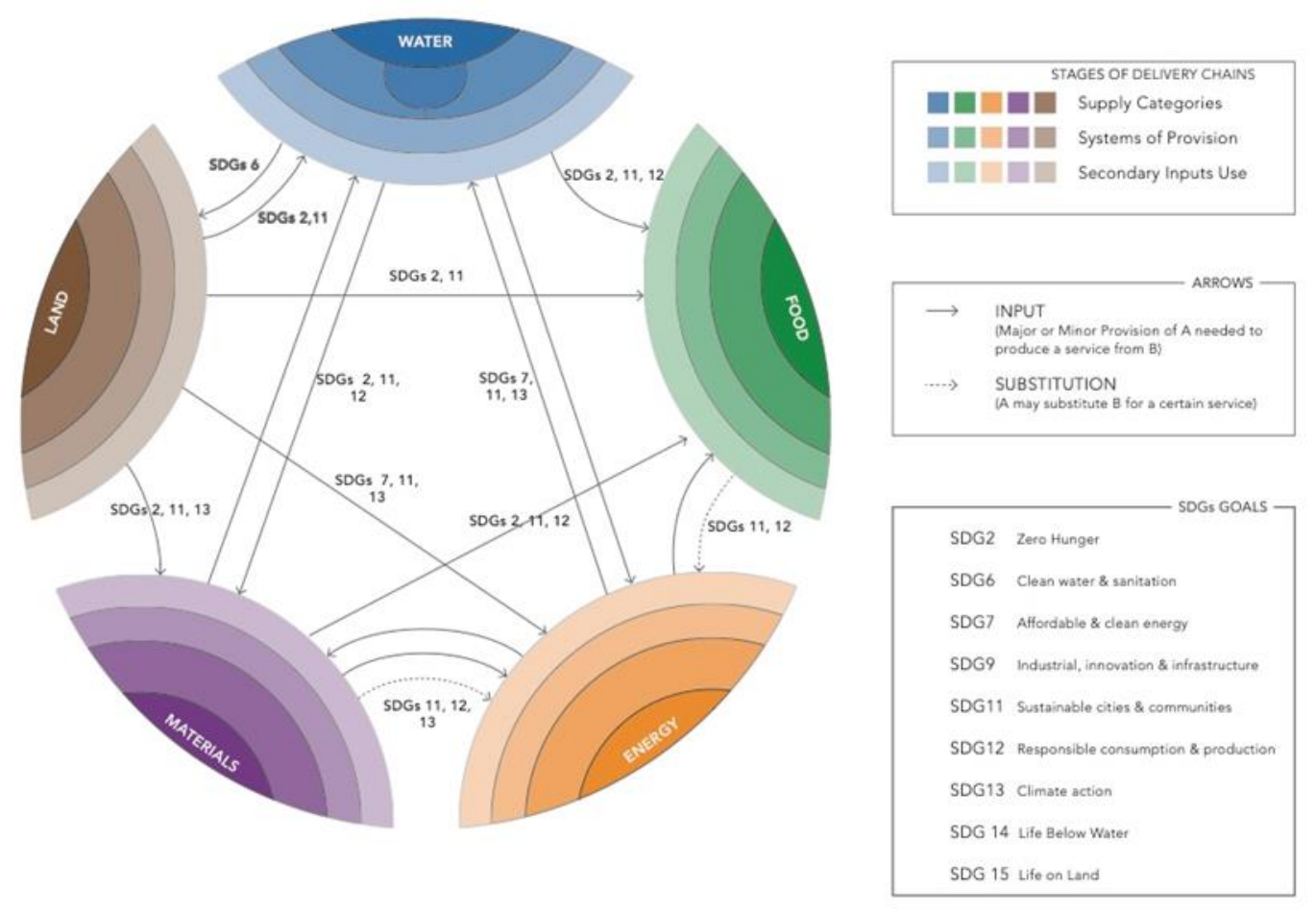

Figure 2: The Resource Nexus

Source: Bleischwitz et al. 2018.

Based on current research, the nexus is a useful tool helping to assess trends and to identify expected bottlenecks for security of supply. It needs further development to assess criticalities and their impacts. Future limitations in the availability of water, the transformations of the energy sector towards low carbon and wider nexus ramifications can lead to 
systemic risks for resource availabilities. How will a 'social license to operate' be affected, if biosphere integrity and local livelihoods are at risk? The minerals industry is increasingly worried about the need to obtain new permissions in light of public concerns ( $C B I$ 2018). Moreover, will a water-stressed region that is being driven into social unrest in a fragile country be able to maintain capacities to deliver materials of sufficient quality and in time? Which regions are at particular risk due to social unrest, governance instability or resource availabilities? Such future risk assessments will need to go beyond geological availabilities and the calculation of 'reserves', (being thought of as reserves that are economically feasible to extract), and they will need to extend risk assessments related to a 'resource curse' of resource-rich developing countries due to corruption and institutional failures (see here e.g. the work of the Natural Resource Governance Institute, NRGI).

Rather, the nexus challenges and new scarcities require interdisciplinary research at the interface of resources, environmental and socio-economic methods and - in a broader perspective - a world-wide mapping of suppliers and geopolitics (Bleischwitz et al. 2014). Industrial Ecology is well placed to study embodied material use and other footprints in up- and downstream operations via environmentally-extended input-output analysis, to assess interdependencies and vulnerabilities of supply (Vivanco et al. 2017; Tukker et al. 2016). As a result, research should be able to extend the established Resource Governance Index that measures the quality of governance in the mining sector in 81 countries $^{1}$ into international environmental relations with users; it should also be able to develop novel tools for corporate reporting against future risks.

New frontiers arrive through limits to Input-Output-Analysis and the need to strengthen the spatial dimension, in order to capture local and regional stress and analyses key actors along supply chains. Bottom-up MFA approaches for urban areas (Schiller et al. 2018) are an innovative complement to global analysis, and soft-linking both will require efforts from many researchers. New approaches of a Life-Cycle Sustainability Analysis (v.d. Voet \& Guinee 2018) could help to explore opportunities for livelihoods. Consequently, research may stress resilience coming from domestic supply, in particular locally available minerals in contrast to imported biotic or abiotic materials. This will also underline the need for governance and novel methods, some of which are highlighted below.

\section{A matter of weight?! Reconsidering sand and cement}

Industrial Ecology has made valuable contributions to material flows and their environmental impacts, quite often around the contested issue of weight (Matthews et al. 2000; v.d. Voet 2004). Perhaps it is now time to reconsider. While a key indicator such as Domestic Material Consumption (DMC) clearly has a bias towards construction materials it also becomes clear that the SDG 11 on sustainable urbanization as well as climate action (SDG 13) and adaptation will require tons of construction materials for establishing and maintaining infrastructures, and their resilience against extreme weather and flood prevention. Addressing minerals, the UK industry urges policy makers to make a link between the need for more and better housing and infrastructure and the raw material supply chain that enables them to be delivered, warning that increasing demand for aggregates is unlikely to be met as permitted reserves are declining steadily and not being replenished at an equivalent rate (CBI 2018).

Cement has been the key material for construction. If the world moved to a per capita production of cement compared to standards of developed countries, which are around 0.6 
metric tons ${ }^{2}$ per capita and per annum it would reach around 4.6 billion tons annual production. Interestingly, the world cement production is expected to increase to 4.83 billion tons in 2030, or perhaps even more as estimated by Christman (2018). A reason for such rapid catchup process is the enormous cement production in China, which is at 2.5 tons per capita and dwarfs the levels currently observed in the industrialized countries. It is estimated that between 2011 and 2013, China used more cement to pave its way towards development than the US did in the entire 20th century. The 'Belt and Road Initiative' and the set-up of the Asian Infrastructure Development Bank indicate an appetite for more infrastructure connecting Asia, East Europe, South-East Asia, and other parts of the world. As expressed above, a key question for foresight on the future demand for materials is the question on any saturation level for materials (Bleischwitz et al. 2018a) in general and in China in particular as well as on eco-innovation pathways for construction materials (see on concrete: Lehne and Preston, 2018).

Within such analysis about expected demand for minerals and construction materials, sand returns as a concern. This may or may not come as a surprise. Concrete, i.e. the finished product for which cement is the binder, is the main driver for sand demand worldwide. The concrete required to build a house uses on average 200 tonnes of sand, a mile of a highway requires 15,000 tons. ${ }^{1}$ Even more sand might be needed to provide resilient infrastructures, like flood defenses, or soils stabilization to withstand hotter temperatures and weather extremes, and to reduce landslides. Chinese Poyang Lake has started dredging due to Chinese cement production. Major island building projects in Dubai led to depletion in the sea floor around Saudi Arabia, so that sand from Australia needed to be imported. Extracting and collecting sand from river beds and sea beds damage microorganisms feeding the base of the food chain. Further indirect impacts are shore communities open to flooding and erosion. In the absence of good regulation of sand extraction across countries, illicit trade with sand has started to emerge (Torres et al. 2017; Beiser 2018).

What is new is the dimension of international trade for heavy materials such as sand, which has been less important in earlier decades when sand was thought of as being available almost abundantly and in every region. But granularity and other quality features of sand availability matter. Now with excessive demand and some local scarcities, the transportation costs become less relevant and hence international trade is on the rise. In a similar vein, the international trade with water has been rising over the last ten years and can be expected to rise further due to regional water stress driven by impacts of climate change.

Parts of industry are ready to pioneer changes. The World Business Council on Sustainable Development (WBCSD) has been running a cement initiative for many years reaching out especially to industry in emerging economies. Low carbon concrete and cement can make use of alternative fuels and improves energy efficiency via dry-kiln with pre-calciner. It can recover waste heat, efficient grinding processes, etc., and would use less water; altogether it could reduce operational costs by $15 \%$. Novel types of cement are available that could absorb $\mathrm{CO}_{2}$ (UNEP 2016). Lightweight skyscrapers can make use of 'carbon-neutral' timber and bamboo that will need to be produced in a sustainable manner with re-use options at the end of the life time. To become more resilient, more permeable materials e.g. for pavements are needed to lower flooding risk; the case of Melbourne with its 'bluestone pavement' might serve as an example. The key to innovation is a mission to sustainability with new pathways

\footnotetext{
${ }^{1}$ Data from Business Insider, The world is running out of sand - and there's a black market for it now, 11 June 2018.
} 
and economic incentives supported by a larger alliance of manufacturing, waste producers, policymakers and researchers that comprehensively address the system of supply chains and building regulations (Bleischwitz and Bahn-Walkowiak 2007; Kemp et al. 2017; Tangtinthai et al. 2019).

Again, Industrial Ecology can play a leading role in research about the life cycle of construction materials, its environmental impacts and its users across a number of applications, as well as future sustainable management. Building upon existing strengths of working with multi-regional input output tables, Industrial Ecology could support deriving tools for construction industry and urban development planners that minimize the use of sand and other environmentally-intensive materials, promote a more circular economy (Geng et al. 2019) across regional users and at a global scale, and enable the market introduction of sustainable construction materials with new business models, 3D printing, reuse and recycling of demolition waste. Assimilating local knowledge will be useful too, as evidenced through experience from traditional flat mud roofs that are good at absorbing and evaporating rainwater.

\section{More resilient infrastructures}

Extreme weather and impacts of climate change can be considered stress tests for the infrastructures that underpin modern societies and, therefore, put at risk achieving SDG9 on resilient infrastructures and inclusive and sustainable industrialization and SDG11 on sustainable cities in all countries. Interdependencies and systemic risks may arise through ICT and transportation, e.g. for food security of private households. After the hurricane Sandy in 2012, for instance, parts of New York experienced cascading effects from power outages leading to shortages in cash, food, and fuel. In the age of climate change, there could be cascading failures through a range of infrastructure breakdowns with indirect damage costs exceeding what had been estimated in traditional risk assessments, and it could all be exacerbated through vulnerabilities and abrupt price peaks in international supply chains and through events happening in remote parts of the world.

Roughly \$2.5tn a year is spent on infrastructure and planned to last for a couple of decades. A systems approach to sustainable infrastructures is needed to align requirements for adaptation with future smart grids and other forms of more intelligent energy systems able to cope with a large share of renewable energies and their distribution. A system view will have to go beyond physical infrastructures such as the built environment, roads and distribution systems for energy and water. This will address the role of ICT, big data and knowledge for an advanced industry, reinforcing the need to address minerals and critical materials. A systems approach to climate change risk assessment of infrastructure has therefore been developed that comprises a number of stages (Dawson et al 2018) analyzing climate variabilities, vulnerabilities of infrastructures, potential knock-on effects, interdependencies, and systemic risks. For the future, it could be expected that planners, utility providers, local and national authorities carry out regional, sectoral, and national risk assessments along the lines outlined above. Tools founded on Industrial Ecology and nexus analysis principles that help to understand risks in both a regional and a geopolitical dimension, and to explore potential pathways towards resilient infrastructures are needed.

Concepts promoted by UN Habitat, the various sustainable cities initiatives (e.g. C40, ICLEI, Future Earth Urban Knowledge Action Network) and concepts such as urban land teleconnections (Schiller et al. 2018) all go beyond low carbon and seek to develop systemic changes. The nexus approach (see figure 2) can be applied at local and regional scales and 
helps to trace linkages between the built environment, water, energy and food. For instance, China's 'sponge city' initiative helps to reduce urban flood risks by increasing green spaces, restoring wetlands and using permeable materials to absorb rainwater and delay runoff (Bai et al. 2018). Alongside with developing such novel materials and applying it through architecture and planning, the buried network of pipelines, cables, and hidden spaces of underground need to be mapped.

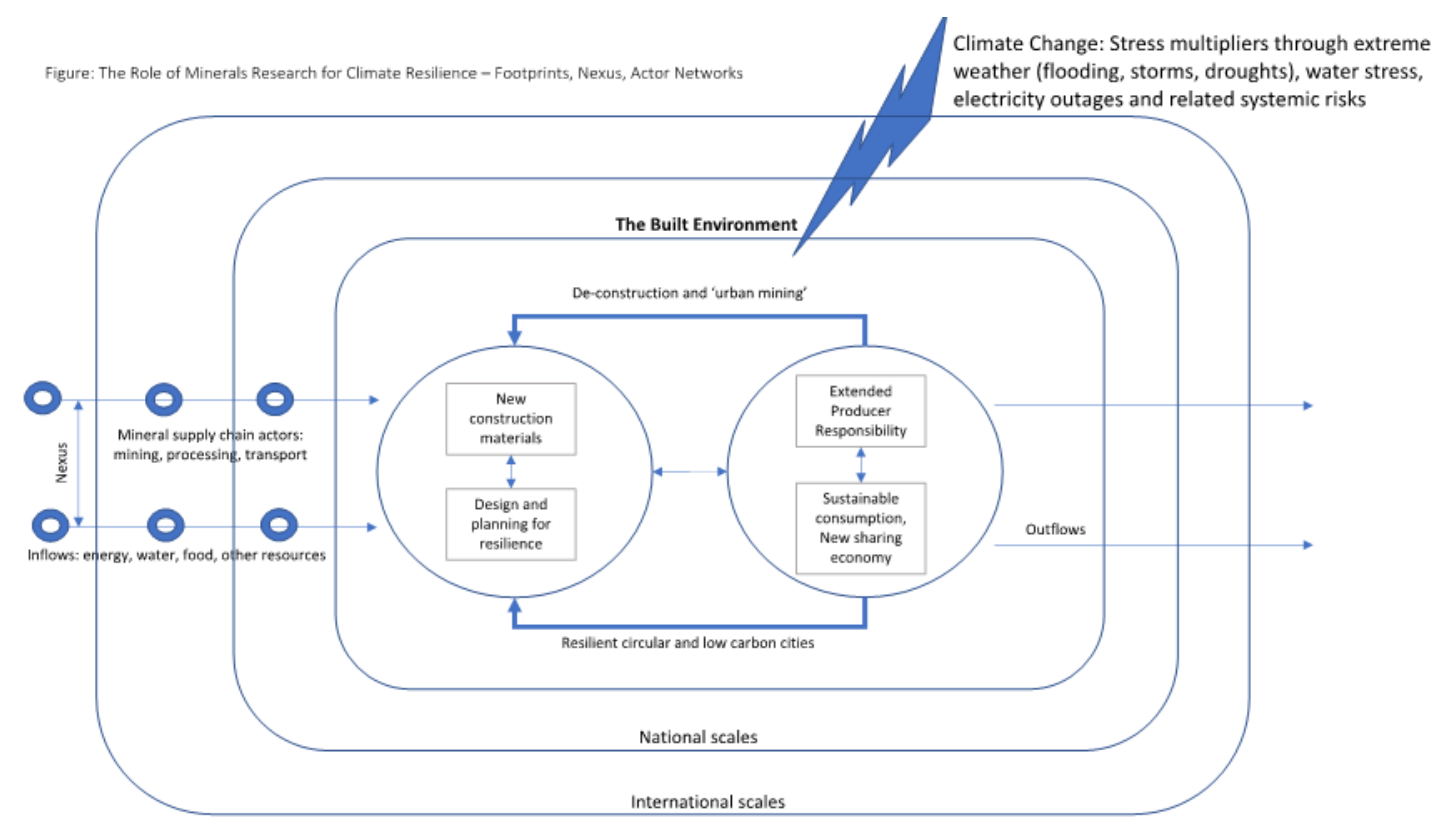

Figure 3: The Role of Minerals Research for Climate Resilience - Footprints, Nexus, Actor Networks

Source: own compilation.

There are many relevant research perspectives for Industrial Ecology in analyzing resource implications of more resilient infrastructures and supporting assessment tools that are needed: 1 . tracing the inputs of minerals, energy, water, and other resources via footprint analysis along supply chains; 2 . assessing resource interlinkages along chains of delivery via nexus analysis and adding a spatial dimension to assess vulnerabilities; 3 . adding actors and their networks to capture attitudes and different speeds of adaptation and innovation. Economists and accountants should also reconsider the valuation of assets in light of climate risks, and planning requirements for maintaining access to minerals reserves (CBI 2018).

\section{The governance of resources}

Addressing the socio-economic dimension of managing minerals is clearly important in order to match supply and demand - cost curves and commodity price analysis are established and research increasingly addresses international value chains, wider demand patterns and macro-economic implications. In addition and with regards to the SDGs, people and policies matter too. The energy transition and a transformation towards a circular economy will come 
at different speeds dependent on how actors take on challenges and innovate, how policies unfold, and how citizens trigger action in different regions of the world. To underline the latter, one may think of responses to heavily polluted cities, the sustainable consumption agenda, quests for stating a 'climate emergency' and the socio-political movement of 'extinction rebellion'. Fig 3 gives an impression about stages in the life cycle of minerals when people matter: at the cradle when a 'social license to operate' ought to be obtained, along supply chains for management decisions, and then after processing minerals into products for construction and the built environment when purchasing decisions are being made and concepts of sharing and re-use are applied. Mineral economics and policy (Tilton and Guzman 2016) will benefit from an extended scope into analyzing patterns of final demand. Governance includes alliances and policy-making at different levels (Bleischwitz and Bahn-Walkowiak 2007; Kemp et al. 2017; Tangtinthai et al. 2019).

Analyzing stakeholders, therefore, is a key to understand and optimize systems as well as to transformations. In line with for example New Institutional Economics and Nobel laurate Elinor Ostrom, actors' rationality is imperfect and strategy development requires learning and time. Analyzing users will go beyond surveys and interviews and there is potential for methodological novelty, developing benchmarks on 'what works', and applying insights for foresight analysis. On the socio-economic dimension, econometric analysis of competitiveness, resource use and greenhouse gas emissions is progressing along with enhanced data availability and methodological advancements (Flachenecker, Rentschler 2018). If, for instance, energy-intensive industries such as steel and aluminum become more 'circular' the global ramifications with winners and losers and environmental impacts might differ widely (see Winning et al. 2018 on steel); a critical variable is the demand for electricity that comes with more use of secondary steel, and whether such demand is met by coal or clean energy. Wider socioeconomic perspectives would address risks of conflicts and the cultural dimension of resilience, thus contributing to methodological novelties. For a start, research should assess actors along supply chains of main construction materials and assess eco-innovation opportunities for resource efficiency. Depicting the role of actors is critical in modelling too, as decision making shifts from goals and targets onto implementation and transitions.

The remarks on risk assessments above imply capacity building on foresight analysis. Foresight research should address different dimensions including 'shock scenarios' that take into account cascading failures of critical infrastructures and conflicts; new 'business as usual scenarios' incorporating saturation effects and/or adaptation to climate change; ambitious scenarios blending smart adaptation, abatement and a circular economy; and, finally, review scenarios for interim assessments (Bleischwitz et al. 2018b). Such capacity building will need to include knowledge on data and modelling in relation to socio-technical systems and governance; it can apply tools of machine learning and artificial intelligence as well. Beyond research, foresight will need an underpinning by international organizations and co-creation with stakeholders. The International Energy Agency has developed a reputation on its energy outlooks - and yet there is no counterpart for minerals. Visible organizations on minerals comprise UNEP's International Resource Panel, the Natural Resource Governance Institute, and - with limitations - the Green Growth Knowledge Platform (GGKP). If they engaged in more foresight analysis, actors on the ground will benefit and steps can be taken to integrate 
minerals into the United Nations Sustainable Energy for All Initiative (SE4All), Integrated Water Resource Management (IWRM) and into the global strive for accountability and sustainable sourcing.

\section{Conclusions}

Looking at the evidence and issues discussed by this editorial it can be concluded that the importance of a mineral resource perspectives need to be raised to achieve climate change adaptation, resilient infrastructures, and sustainable cities. Life-cycle assessments and material flow analysis of supply chains for construction materials are needed for planning the urban space of tomorrow. The research perspective presented here brings together strands of industrial ecology with natural resources research and socio-economic perspective. Moving from regional cases and single resources into a systems perspective, Industrial Ecology could develop a better grasp of the spatial dimension of material flows, partly to track those flows and align it among actors, and partly to address international supply chains and trade.

A related perspective comes with interlinkages across different flows and their stocks in society ('the resource nexus') and will be decisive for a successful achievement of the SDGs, in particular for pursuing sustainable cities and climate change action along SDGs 11 and 13 in alignment with SDGs on water (SDG6), energy (SDG7), responsible consumption (SDG12), and land use (SDG15). Methodological innovations around Industrial Ecology should strengthen socio-economic governance dimensions and would enable foresight studies on sustainable materials for the delivery of the SDGs. Pursuing such perspective should ultimately increase the resilience of entire urban systems.

It is clear that climate adaptation has significant resource implications, and how resources are being used has implications on climate strategies. Addressing the role of mineral resources for strategies of resilience can and should generate co-benefits. A combination of bottom-up studies, comparative assessments, governance and foresight should be able to generate strategic options and pathways for key actors. Doing so, research could come up with tools for regional planners and industry. In such perspectives future research in and around Industrial Ecology towards resilient and sustainable provisioning services in urban areas for the delivery of SDGs and beyond is needed.

\section{Acknowledgements}

I am grateful for excellent management and feedback from Oliver Heidrich throughout the whole process, as well as for comments provided by Eva Bartekova on a first draft. Four anonymous reviewers have greatly shaped the outcome of this paper, from a probably weak first version onto the current one that is hopefully more insightful and stimulating for readers. Thanks also for last comments made by editors.

\section{References}


Adger, W.N. et al. 2014. Human security. In: Climate Change 2014: Impacts, Adaptation, and Vulnerability. Part A: Global and Sectoral Aspects. Contribution of Working Group II to the Fifth Assessment Report of the Intergovernmental Panel on Climate Change.

Ali SH et al. 2017. Mineral supply for sustainable development requires resource governance, Nature, March 2017, doi:10.1038/nature21359.

Bai, X. et al. (2018) Six research priorities for cities and climate change, Nature 555, $23-25$.

Beiser, V. 2018. The World in a Grain: The Story of Sand and How It Transformed Civilization, Penguin Random House.

Biggs, E. M. et al. 2015. Sustainable development and the water-energy-food nexus: A perspective on livelihoods. Environmental Science \& Policy 54, 389-397, doi:http://dx.doi.org/10.1016/j.envsci.2015.08.002 (2015).

Bleischwitz, R., Johnson, C. M., and Dozler, M. G. 2014. Re-assessing resource dependency and criticality. Linking future food and water stress with global resource supply vulnerabilities for foresight analysis. European Journal of Futures Research, 2(1), 15 - 34.

Bleischwitz, R., Hoff, H., Spataru, C., vd Voet, E., VanDeveer, S. (Eds.) 2018. Routledge Handbook of the Resource Nexus.

Bleischwitz, R. and Bahn-Walkowiak, B. 2007. Aggregates and Construction Markets in Europe: Towards a Sectoral Action Plan on Sustainable Resource Management, Minerals and Energy 3-4, $159-176$.

Bleischwitz, R. and Rentschler, J. 2018. Scarcities, supply and new resource curses? In: Bleischwitz et al. (Eds.) (2018): Routledge Handbook of the Resource Nexus, chapter 19.

Bleischwitz, R. et al. 2018a. Extrapolation or saturation - Revisiting growth patterns, development stages and decoupling, Global Environmental Change 48: 86-96.

Bleischwitz, R. et al. 2018b. Resource nexus perspectives towards the United Nations Sustainable Development Goals, Nature Sustainability, https://doi.org/10.1038/s41893-0180173-2

CBI (Confederation of British Industry) 2018. UK Minerals Strategy: Meeting the demand for minerals and mineral products sustainably for the next 25 years. A Strategy prepared by the UK minerals and mineral products industry, facilitated by members of the $\mathrm{CBI}$ Minerals Group and the Mineral Products Association.

Christman, P. 2018. Towards a More Equitable Use of Mineral Resources, Natural Resources Research (27) 2: 159 - 178. DOI: 10.1007/s11053-017-9343-6

Dawson RJ et al. 2018 A systems framework for national assessment of climate risks to infrastructure. Phil. Trans. R. Soc. A 376: 20170298.

http://dx.doi.org/10.1098/rsta.2017.0298

Farrell, J. (2016) Corporate funding and ideological polarization about climate change, PNAS 113:1, $92-97$.

Flachenecker, F., Rentschler, J. (Eds) (2018) Investing in Resource Efficiency. The Economics and Politics of Financing the Resource Transition, Springer. 
Hatfield-Dodds, S. et al. 2017. Assessing global resource use and greenhouse emissions to 2050, with ambitious resource efficiency and climate mitigation policies. Journal of Cleaner Production 144: 403 - 414.

Kemp, R. et al (2017) The innovation trajectory of eco-cement in the Netherlands: a co-evolution analysis, International Economics and Economic Policy DOI 10.1007/s10368-0170384-4

Lehne, J., Preston, F. 2018. Making concrete change: Innovation in low-carbon cement and concrete. A Chatham House Report, London.

Li, F., Strachan, N. 2019. Take me to your leader: Using socio-technical energy transitions (STET) modelling to explore the role of actors in decarbonisation pathways, Energy Research \& Social Science 51: 67-81.

Matthews et al. 2000. The weight of nations, World Resources Institute.

Meinert, L. D., Robinson, G. R., and Nassar, N. T. (2016). Mineral resources: Reserves, peak production and the future. Resources, 5, 14. doi:10.3390/resources5010014

Nickless, E. 2016. Resourcing future generations: A global effort to meet the world's future needs head-on. European Geologist, 42, 46-50.

Northey, S.E., Mudd, G. M., Werner, T.T. (2018). Unresolved complexity in assessments of mineral resource depletion and availability. Natural Resources Research (27:2) 241 255. DOI: 10.1007/s11053-017-9352-5

OECD 2018. Global Material Resources Outlook to 2060. Economic drivers and environmental consequences (Highlights). Paris.

UNEP 2010. Assessing the Environmental Impacts of Consumption and Production: Priority Products and Materials, Hertwich E. et al

UNEP 2016. Eco-efficient cements. Potential, economically-viable solutions for a low- $\mathrm{CO}_{2}$, cement-based materials industry, by Karen L. Scrivener, Vanderley M. John, Ellis M. Gartner, Paris.

UNEP 2017. Resource Efficiency: Potential and Economic Implications. A report of the International Resource Panel. Ekins, P., Hughes, N., et al.

Schiller, G., Bimesmeier, T., Han Thuc Tran 2018. Bridging urban-rural dichotomy following building material flows of urbanisation. Proceedings of the 12th World Congress of the RSAI, p. 1596 - 1603. ISBN 978-989-54216-0-2

Steffen, W. et al. 2018. Trajectories of the Earth System in the Anthropocene, PNAS, doi/10.1073/pnas.1810141115

Tangtinthai, N., Heidrich, O., Manning, D. 2019. Role of policy in managing mined resources for construction in Europe and emerging economies, Journal of Environmental Management 236: 613-621.

Tilton, J. E., Guzman, J. 2016. Mineral Economics and Policy, New York.

Tokimatsu, K. et al. Energy modeling approach to the global energy-mineral nexus: A first look at metal requirements and the $2^{\circ} \mathrm{C}$ target. Applied Energy 207, 494-509, doi:https://doi.org/10.1016/j.apenergy.2017.05.151 (2017). 
Torres, A. et al. 2017. A looming tragedy of the sand commons. Increasing sand extraction, trade, and consumption pose global sustainability challenges. Science (357) 6355: 970 $-971$.

Tukker, A., T. et al. 2016. Environmental and resource footprints in a global context: Europe's structural deficit in resource endowments. Global Environmental Change 40: 171-181.

Font Vivanco, D., R. Wang, and E. Hertwich. 2017. Nexus strength: A novel metric for assessing the global resource nexus. Journal of Industrial Ecology http://doi.org/10.1111/jiec.12704.

Murgia, D., Bringezu, S., Schaldach, R. 2016. Global direct pressures on biodiversity by largescale metal mining: Spatial distribution and implications for conservation, Journal of Environmental Management 180: $409-420$.

Schroeder, P. et al., (2018). The Relevance of Circular Economy Practices to the Sustainable Development Goals. Journal of Industrial Ecology doi.org/10.1111/jiec.12732

Voet, E. van der, and Guinée, J. B. (2017). Life cycle assessment, life cycle sustainability analysis and the resource nexus. In: Bleischwitz et al. 2018, Chapter 5.

Voet, E. v.d. 2004/2008. Dematerialization - Not just a matter of weight, Journal of Industrial Ecology 8 (4): 121-137.

Wiedmann TO, et al. (2013) The material footprint of nations. PNAS, doi:10.1073/pnas.1220362110.

\footnotetext{
${ }^{1}$ Provided by the Natural Resource Governance Institute (NRGI); see: https://resourcegovernanceindex.org/

${ }^{2}$ All tons are in this article are metric tons. One metric ton $\approx 0.907$ short tons.
} 